\title{
The embeddedness of digital infrastructures for data collection by the Courts of Accounts*
}

\author{
André Carlos Busanelli de Aquino ${ }^{1}$ \\ (D) https://orcid.org/0000-0002-0329-410X \\ Email: aaquino@usp.br
}

\author{
André Feliciano Lino ${ }^{2}$ \\ (D) https://orcid.org/0000-0003-1121-4971 \\ Email: aflino@ufpa.br
}

Ricardo Rocha de Azevedo ${ }^{3}$

(D) https://orcid.org/0000-0001-6302-0760

Email: ricardo.azevedo@ufu.br

\author{
${ }^{1}$ Universidade de São Paulo, Faculdade de Economia, Administração e Contabilidade de Ribeirão Preto, Departamento de Contabilidade, \\ Ribeirão Preto, SP, Brazil \\ ${ }^{2}$ Universidade Federal do Pará, Instituto de Ciências Sociais Aplicadas, Departamento de Ciências Contábeis, Belém, PA, Brazil \\ ${ }^{3}$ Universidade Federal de Uberlândia, Faculdade de Ciências Contábeis, Uberlândia, MG, Brazil
}

Received on 03.09.2020 - Desk acceptance on 04.22.2020 - $2^{\text {nd }}$ version approved on 03.29.2021 - Ahead of print on 09.15.2021

Editor-in-Chief: Fábio Frezatti

Associate Editor: Eliseu Martins

\begin{abstract}
This study aimed to identify the trajectories for data collection automation in various Courts of Accounts (Tribunais de Contas), the standard features of the systems that have emerged, and the impacts on fiscal and accounting oversight in Brazil. Data collection automation is part of the digital transformation in the field of auditing; however, the literature on public sector auditing in Brazil, on digital transformation, or digital infrastructure, does not analyze how this transformation occurs and how the infrastructures are stabilized and shape the field of auditing. Data collection automation has unexpected implications for the content of public sector audits and the financial management of the public sector auditees. Identifying the trajectories for digital tools of data collection automation enables a discussion on whether currently adopted solutions vary and the effects on the standardization of government audits. The automation of data collection by the Court of Accounts, particularly its scope and frequency, affects how the audited public organizations prioritize the adoption and maintenance of accounting, budgeting, and financial planning policies and processes. The digital infrastructures that emerge from these digital tools shape the entire field of auditing, they become embedded, and they increase the cost of future changes, perpetuating the heterogeneity in the auditing and financial management of governments in the Brazilian federation. The article presents a longitudinal case study (1994 to 2020), with narratives built based on questionnaires and interviews with auditors from 26 Courts of Accounts. The automation of budgetary and accounting data collection by Courts of Accounts has changed the logic of the field of government auditing in Brazil. The digital infrastructures that emerge by connecting Courts and the audited public organizations under their jurisdictions have embedded concepts, definitions, and implicit expectations in a remote auditing logic.
\end{abstract}

Keywords: Court of Auditors, public sector auditing, accounting, e-government.

Correspondence address

André Carlos Busanelli de Aquino

Universidade de São Paulo, Faculdade de Economia, Administração e Contabilidade de Ribeirão Preto, Departamento de Contabilidade Avenida Bandeirantes, 3900 - CEP 14040-900

Monte Alegre - Ribeirão Preto - SP - Brazil

\footnotetext{
* A previous version of this article was presented at the 16th USP International Conference in Accounting, São Paulo, SP, Brazil, July 2016. We are grateful to Anna Paula da Silva Moreira and Ícaro Saraiva Laurinho for their careful working on data validation, to the members of the Public Sector Accounting and Governance research group for their valuable comments, to the auditors from the many Courts that participate as respondents, and also to both reviewers.
} 


\section{INTRODUCTION}

Audit organizations have been increasingly relying on technology to carry out their processes. For example, auditors are already known to have adopted computerassisted audit tools and techniques in their data analyses (Bradford et al., 2020). Regarding the public sector, since the end of the 1980s, the International Organization of Supreme Audit Institutions (Intosai) has promoted the use of such tools in government audits to increase efficiency and automate repetitive, structured, and labor-intensive tasks (Huang \& Vasarhelyi, 2019).

Previous studies on audit automation usually focus on the data analysis stage and are spread over different areas of knowledge (Alles \& Vasarhelyi, 2007). Recently, studies on digital transformation (Mergel et al., 2019) and digital infrastructure (Furneaux \& Wade, 2011; Fürstenau et al., 2019) have analyzed how this transformation occurs and stabilizes in various empirical contexts; however, they have not covered the field of auditing.

In Brazil, over the last three decades, the Courts of Accounts (Tribunais de Contas) have increasingly adopted electronic systems to automate the collection of data from public sector organizations to carry out various types of auditing. In general, data collection automation in Brazil preceded data analysis automation, which is still in an initial stage in many Courts. It is data collection automation that has given rise to the digital transformation currently underway. This automation is one example of digital transformation (Mergel et al., 2019), as it has had significant, continuous, and increasing effects due to the combination of computing, information, and connectivity technologies.

We define data collection automation as the introduction of electronic communication protocols during the auditee's oversight process. These protocols form the interface between the issuer and receiver of the fiscal, budgetary, and accounting data. In general, the Courts use a digital tool (or just 'systems') through which the audited public organizations send their information to be analyzed by the auditors - called data collection system (DCS). According to the current legislation in the country, those systems are used by other organizations with a legal mandate to oversee government accounts, such as fiscal authorities. In Brazil, besides the Courts of Accounts, the federal government also uses similar systems to receive information on budget execution and public policies of local governments, such as the Health Ministry [Public Sector Health Budgets Information System (Siops)], the Education Ministry [Public Sector Education Budgets Information System (Siope)], and the National Treasury Secretariat [System of Fiscal and Information of the Brazilian Public Sector (Siconfi)]. One international example of electronic data collection from governments is the Budgeting, Accounting, and Reporting System of the state of Washington in the United States of America (State Auditor's Office [SAO], 2021, March $9^{\text {th }}$ ).

By automating and making data collection remote through DCSs, the Courts of Accounts obtain benefits by overcoming constraints on time and resources needed for collecting, storing, and using increasingly comprehensive and more frequent information. For instance, digital storage replaces the custody of paper documents. Moreover, the transfer of paper documents no longer depends on physical means; instead, it relies on data transmission protocols (Reis et al., 2015).

However, how this transformation occurs, the innovation trajectories, and the implications have yet to be examined and are critical for better coordinating the digitalization of public sector audits in the country. Therefore, this study examines the emergence and proliferation of DCSs in the Courts and how these become digital infrastructures for organizing the auditing tasks. We adopt two concepts to understand such phenomena. First, the digital infrastructure is a set of individual but interconnected digital tools or computational systems that jointly evolve (Fürstenau et al., 2019). Second, path dependence is a possible explanation for the embeddedness of these infrastructures in each Court and the field of auditing.

The article analyzes the trajectories towards automation of data collection by the Courts of Accounts in Brazil, responsible for oversight of municipal governments. The article also describes the standard features and principles of the various DCSs that have emerged from the Courts' initiatives to improve the audit process. Finally, it discusses some of the implications of this scenario.

We conducted a longitudinal case study of the data collection automation engendered by 26 Courts of Accounts, covering 1994 to 2020 . The research counts on interviews with directors and senior civil servants who work with information and communications technology (ICT) in these Courts, triangulated with public documents and a questionnaire sent by the authors.

The results indicate that data collection automation evolved through a series of investments (in software, human resources, and handbooks) that the Courts made to develop their DCSs. Based on these DCSs, digital infrastructures have emerged and are pushing a broad digitalization of the public sector auditing process. These digital infrastructures include financial management systems in the municipalities, which send and provide data for remote auditing by the auditors of the Courts. Each infrastructure developed around the various Courts' DCSs. 
Those infrastructures have received investment from the Courts themselves and financial management software developers, and auditees. Those auditees (e.g., public sector organizations being audited) usually cover the costs of continually adapting the software and processes.

We identified eight different automation trajectories which the Courts followed in adopting and developing their DCSs. Those trajectories led to the convergence of core concepts and a specific logic for collecting data from audited organizations as an essential part of the public sector auditing model currently used in the country. Despite this convergence, the article brings out the implications of this transformation.
The article briefly presents the context of the government oversight process, precisely the process that has been automated and that has given rise to the digital transformation currently underway in the field. Next, the concept of path dependence is presented as a central mechanism for configuring the development trajectories of the DCSs and, consequently, in the digital infrastructures. After the methodology section, we dedicate two sections to explaining the configurations and trajectories of the DCSs currently used by Courts. Subsequently, we discuss the argument that the DCSs give rise to digital infrastructures that enhance the embeddedness of those systems. We end by presenting some implications and conclusions.

\section{THE CONTEXT OF GOVERNMENT OVERSIGHT PROCESS BY THE COURTS OF ACCOUNTS}

The various reporting requirements on Brazilian municipalities lead to a regime of accountability overload (Halachmi, 2014). Various public sector organizations have some degree of reporting activities to the Courts of Accounts. However, this overload primarily occurs in city halls because of the extent of their activities (as service delivery and many local public policies). Also, city halls are in charge of consolidating the data from their local executive agencies. As city halls provide public services, run public policies, raise taxes, and regulate land use and urban expansion, among other issues, they are accountable for sending increasing volumes of data (even more frequently), both to the Courts of Accounts, to ministries and the National Treasury Secretariat.

The milestone for this context of accountability overload was the introduction of the Fiscal Responsibility Law (FRL) (Complementary Law n. 101, of May $4^{\text {th, }}$ 2000), which gave a more prominent role to the Courts of Accounts regarding the fiscal oversight of governments (Loureiro et al., 2009). Until then, the Courts primarily enforced the legal compliance of administrative procedures taken by local and state governments regarding civil servants' hiring, budget execution, and public procurement. They also oversaw the government's annual accounts. The new FRL requirements pushed the auditing in the Brazilian public audit setting. A relevant movement was the 'Program for the Modernization of the External Control System' (Promoex in the Portuguese acronym), launched in 2005, counting on the support of the InterAmerican Development Bank. The program aimed to develop networks among the Courts, improve the use of information systems, and redesign oversight processes to comply with FRL requirements. Several Courts joined this program (Silva \& Mário, 2018).
However, the Courts have historically assumed a conservative and entrenched posture, almost exclusively focusing on compliance/legal auditing (Azevedo \& Lino, 2018). They have drawn criticisms for their excessively political logic of action (Loureiro et al., 2009) and nepotism, clientelism, and corrupt practices (Lino \& Aquino, 2020). Despite following the same organizational architecture and audit model, the various Courts of Accounts spread throughout the national territory have different understandings of the fiscal and budgetary regulations (Nunes et al., 2019; Teixeira, 2020) and levels of enforcement (Lino \& Aquino, 2018).

The typical fiscal oversight process that the Courts of Accounts have institutionalized can be described in a simplified three-stage process. In the first stage, public organizations, such as municipal governments, compulsorily send data to the Court with the frequency and scope defined by the Court. In the second stage, the data stored are used by auditors running remote audits. In the third stage, the Court's Magistrates board judge the compliance of auditees to the regulation (or performance, in some specific oversight processes), based on the reports prepared by auditors, and issue an audit opinion and recommendations to the auditee with corrective measures or sanctions (the "court's report").

Data collection automation occurred precisely in the first stage of the process mentioned, substituting the previous paper reporting (analogical format) of financial reports and the procurement documents (Reis et al., 2015). Initially, municipal civil servants delivered in person all the data for the oversight process at the Court's headquarters (or regional office). Previously they delivered paper documents in an analogical ritual and then started to use floppy disks to store and transport digital documents and spreadsheets. Subsequently, with electronic 
communication and data transfer protocols of DCSs, data collection and storage became digital and remote. Some Courts then converged to a data-driven audit model, in which the auditing tasks follow the collected data (Arnold, 2018). For example, Courts started to run preliminarily processing of the data collected from city halls and send "non-compliance warnings" to the auditors in charge to audit each municipality (Lino \& Aquino, 2018).

As will be presented, each Court adopted a DCS in its own time. They are currently using different DCS solutions and versions in the country. However, the many DCS in place has standard features. They are systems connected to the internet applying an electronic communication protocol and a previously defined architecture (data layout) to receive data packages sent by auditees. Auditees send data from their Integrated Financial Management Information System (IFMIS) (the acronym in Portuguese applied in the country is 'Siafic' according to Federal Decree $n$. 10,540, 2020, November $5^{\text {th }}$ ). Data collection is different from what is known as "data extraction." On the one hand, DCS receives data from the auditee (e.g., municipality or state); on the other hand, for the data extraction, the auditors use tools to directly access auditees' financial management system to run transactions tests (Teeter et al., 2010). In the Brazilian case, city halls upload the budgetary and accounting data package in the format and frequency required by the Court of Accounts using their IFMIS connected to the Court's DCS.

Each city hall has the autonomy to choose its IFMIS. The solution commonly adopted by municipalities in the country is to outsource the IFMIS using a commercial software licensing agreement, in which the supplier covers the costs for adapt the system according to the changes constantly imposed by the Court of Accounts (Aquino, Azevedo, Lino \& Cardoso, 2021; Azevedo, Lino, Martins \& Aquino, 2020).

Finally, a digital infrastructure emerges as the central module of the IFMIS in which the auditees connect to the DCS and provides data for the auditors' data analysis tasks. This digital infrastructure will support and induce the data-driven audit in each Court, enabling the expansion of the remote auditing logic in the field. The choices made when developing the DCS are at the origin and the center of the digital infrastructure.

\section{PATH DEPENDENCE OF THE DIGITAL INFRASTRUCTURE}

The development of a new DCS, replications of similar DCSs in various Courts via technical cooperation agreements, discontinuations, and changing DCS version are decisions at the "Court of Accounts" organizational level. However, they affect and are affected by the whole government oversight organizational field (composed of Courts, more than 5,500 municipalities, software suppliers, professional auditors' associations, and other stakeholders). We argue that (i) there is a trajectory for the data collection automation in each Court and (ii) a trajectory for the field of auditing as a whole.

Data collection automation is an innovation applied by the Courts, initially adopted to improve the governmental fiscal monitoring reinvigorated by the FRL. Each Court has autonomously decided on adopting DCSs, and a digital infrastructure has gradually been consolidated and embedded. Such an infrastructure emerged due to interdependent systems evolving in relation to the other systems (Fürstenau et al., 2019). This infrastructure interacts, at one side, with the financial management systems in the governments (IFMIS), at the interface between the Court's DCS with the auditees (municipalities) and, at the other side, with electronic auditing systems (computer-assisted audit techniques and tools [CAATTs]) used by the auditors from that Court. Those infrastructures leave a footprint of their trajectory, as Courts and auditee continuously use them, the individual DCS and IFMIS become part of the routines of those professionals and providers, they are accepted as an integral part of the organizational reality, they cease to be questioned (Fürstenau et al., 2019), and they become embedded. Various digital infrastructures emerge in the Brazilian government oversight field, are developed, and become embedded, depending on those Courts' choices.

Courts that adopt innovation at an initial stage (early adopters) seek productivity gains in their activities (Fligstein, 1985). At subsequent phases, other organizations adopt similar solutions later (late adopters), seeking legitimacy (Scott, 2014; Tolbert \& Zucker, 1983) or in response to the uncertainties raised by solutions not tested yet. One example of these influences that emerge from the oversight organizational field is the already mentioned Promoex, which supported the Courts' innovation in Brazil. Once a solution is adopted by the Court on its DCS, continuous investments raise barriers to changing a trajectory.

We adopt here the concept of path dependence, one explanation offered by the literature to the embeddedness of a digital infrastructure's trajectory (Fürstenau et al., 2019). Path dependence is the property of a stochastic process that emerges in the presence of contingency and self-reinforcement and creates the lock-in effect if there is/was no external shock (Vergne \& Duran, 2010). More than the initial conditions affecting the adoption of a 
solution, the trajectory is shaped by a series of events/ opportunities (contingencies) that drive the decisions (Vergne \& Duran, 2010).

Once the technology has been chosen, considering the contingencies and reinforcing mechanisms for this path can intensify the permanency of the ongoing solution. Some examples are the positive network externalities, increasing returns to scale, scope, or learning (Vergne \& Duran, 2010), or even losses (sunk costs) associated with the other possible alternatives (Kay, 2005).

As these path-dependent mechanisms take effect, organizations that remain on a particular trajectory of development will be locked in a position "that cannot be escaped endogenously" (Vergne \& Duran, 2010, p. 743). An external shock, such as an institutional change [e.g., Schneiberg (2007)], could break the tendency to remain in the same direction. Moreover, the tendency to remain in the same direction will also disrupt if that direction is disturbed and the gains in scale and scope drop (Ruttan, 2001) or when the features of the developed system become inadequate for the current demands due to regulatory or technological changes (Furneaux \& Wade, 2011).

On the other hand, in some situations, "a particular solution is developed so that it is hard, if not impossible, to reverse course or consider using alternative approaches even if they lead to better results" (Scott, 2014, p. 144).

Returning to the concept of embeddedness, the inertia of a digital infrastructure to change trajectory, even with a possible loss of functionality, is strengthened by the extent to which the system is an integral and unquestionable part of the organization's routines (system embeddedness) (Furneaux \& Wade, 2011; Fürstenau et al., 2019). Managers may not even associate the difficulty of changing a digital infrastructure with a loss of investments made or sunk costs or with system switching costs, as Furneaux and Wade (2011) show. Deep embeddedness means the tasks and processes heavily depend on the digital infrastructure interconnected with other organizational systems, and abandoning it becomes almost unimaginable (Furneaux \& Wade, 2011).

\section{METHODOLOGY}

The analysis covered two aspects: (i) the automation trajectory for data collection by Courts of Accounts and (ii) the standard features and principles of the various systems that emerged in the period analyzed. Only DCSs focusing on budgetary and accounting data were analyzed, despite various Courts of Accounts have systems for collecting other types of data, such as public works, biddings, and civil servant hiring. The sample brings together a diverse set of DCSs currently in use (for accounting and budgetary data) and compares how these systems vary in relation to the attributes of a typical DCS being institutionalized in the oversight field. The convergence of features or attributes of this typical DCS would come from isolated initiatives and influences of other solutions in the field (Tolbert \& Zucker, 1983), as the solutions sponsored by each Court sought to extend the automation perceived benefits if Courts accepted (or ignored) the collateral effects of automation on the auditing process.

We conducted a longitudinal case study (Elliott et al., 2008) observing the automation trajectories of the Courts of Accounts in the period from 1994 to 2020. "Automation trajectory" is the set of choices made by a Court of Accounts, from the design and implementation up to the continuous improvement of the versions of its DCS, within the period of analysis. The study focused on 26 Courts of Accounts with jurisdiction over multiple municipalities, based on the classification proposed by Lino and Aquino (2018). We mapped the DCSs initiatives and trajectories via interviews and documents for 26 Courts (Figure 1) and via a questionnaire for 18 of them (Table 1).

\subsection{Data Collection}

The study used documental sources and information collected in questionnaires and interviews. The interviews were carried out firstly in January/February 2016 and secondly in August/September 2018.

\subsubsection{Data collection in 2016}

First, we summarized the main attributes for the typical DCS, identified and collected from the Courts' websites and from a pilot interview with a key informant from one Court of Accounts, to develop an electronic questionnaire (spreadsheet-format). Subsequently, the questionnaire was validated by the key informant and IFMIS consultants. Next, we sent the questionnaire to the ICT departments of all selected 26 Courts and received complete data from 18 of them on whether those main attributes were present on each specific Court. Next, interviews were scheduled with directors and senior civil servants working with ICT in the 18 Courts. We sent formal requests for the ombudsman of those eight Courts that did not fill the questionnaire, to run interviews as an alternative.

A combined approach based on semi-standardized open-ended questions and episodic interviews has been adopted to capture a narrative regarding the "adoption 
and development" of the DCS of that Court. This type of interview associates the concrete event (technological change) with other concrete situations (moment, location, people involved, other contemporary events) experienced by the respondent and, finally, it is associated with the (decontextualized and abstract) knowledge the respondent has (about the DCS) (Flick, 1998; Hermanns, 1995). Based on the narratives, we proposed a concept map (Figure 1) for the trajectories identified using thematic coding (Flick, 1998), showing the sequence of versions adopted by each Court.

The interviews with the Courts started with validation of the characteristics of the current DCS captured by the questionnaire or on the Court's website. Next, the interviewee described the event of DCS adoption. The protocol covered the events associated with the development of the DCS, the context at that time, possible technical cooperation agreements with other Courts of Accounts to grant use of the system, and pressures to adapt the DCS. It also questioned how the DCS was impacted by the national chart of accounts (Chart of Accounts Applied to the Public Sector - Pcasp) imposed by the reform of public accounting that was underway at the time.

In addition, we interviewed auditors from each one of the Courts, lasting an average of 20 minutes (maximum of $1 \mathrm{~h} 18$ and minimum of 10 minutes), as well as additional calls to clarify specific issues. The interviews in this phase were not recorded. However, during the telephone call, one of the authors made notes on an electronic spreadsheet listing the attributes of that DCS. Additional notes were taken during and at the end of the interview. Other triangulation interviews were carried out with IFMIS consultants on DCSs data uploading and one employee from Rui Barbosa Institute, the author of the study which reported the digital infrastructures in use by the Courts of Accounts in 2011.

\subsubsection{Data collection in 2018}

Later in 2018, the authors run the second round of interviews with the previously interviewed Courts, double-checking about changes of DCS versions and how each Court was addressing the National Treasury request to harmonize the DCS with the Treasury DCS (more granular and following a different frame). Courts of Accounts that had not previously participated were also interviewed. The interviews with directors and senior civil servants from 19 Courts of Accounts applied the same protocol lasting about 30 minutes (maximum of $1 \mathrm{~h} 01$ and minimum of 18 minutes). In this stage, all the interviews were recorded and transcribed.

We also categorized each Court according to favorable or unfavorable conditions for early or late adoption of its DCS (Table 1). A favorable context for automation enhances the benefits of early adoption of the DCS. We considered the following factors as the drivers for an early adoption: a lower auditor/auditees ratio, higher geographic dispersion of the auditees, difficult-to-access areas, auditees holding good ICT infrastructure, less internal resistance, or support by leaders. The conditions previously raised by Lino and Aquino (2018) and others were inductively outlined by the interviews.

\subsection{Coding of the Automation Narrative}

The narrative of the automation trajectory of the DCSs (Figure 1) was coded counting on the evidence collected by the episodic interviews. We identified that the trajectory occurs through changes of versions of DCS, understood here as system configurations, features and attributes (e.g., more or less granularity or integrity) through the application of technology (e.g., language, programming and database architecture, communication protocols). There is a certain level of dependence between technology employed and features, such as XBRL structure, which affects its integrity.

In an abductive approach (Reichertz, 2013), we used the previous literature on the use of ICT in the audit setting. Moreover, based on the interviews and questionnaires, we identified the attributes of a typical DCS: structure, integrity, mirroring, granularity, frequency, warnings, and analysis. The attributes correspond to the current version of the DCS in 2016 (Table 1) and the succession of the versions up to 2020 (Figure 1). However, they do not capture the different previous configurations.

\section{ATTRIBUTES OF A TYPICAL DCS}

The results indicate a convergence of the Courts of Accounts to a standard set of DCS's attributes, probably favored by the interaction of the Courts during Promoex. Table 1 compares the attributes of 18 DCSs (structure; integrity; mirroring; granularity; frequency; and warnings and analysis).

\subsection{Structure}

The "structure" associates the data to categories/labels when the data are recorded, giving meaning to a data unit (e.g., own tax revenues). The less vulnerable the dataflow is (recording and storage of data in the IFMIS, extraction and 
subsequent storage of the data by the DCS) and the clearer and more stable the labels used are, the less the auditing process will be susceptible to inappropriate manipulations or misinterpretations (Singleton, 2010). Inappropriate data manipulation is more likely when the structuring level is low, e.g., when the data is transmitted by sending text files or spreadsheets. Data are currently sent in the following ways, ordered from least to most structured: (i) the audited public sector organization, as a city hall, generates information in its IFMIS and enters it into a "client-based tool," which may be the Court's website or other electronic application; (ii) the data are generated and packaged by the IFMIS in a local file, in a pre-defined standard and format (txt, CSV, xls, XML, XBRL), and then the accountant in charge of the process command the IFMIS to transfer the data to the DCS; or (iii) the IFMIS automatically transfers the data to the DCS without any human interference.

\subsection{Integrity}

"Integrity" concerns to the absence of flaws in the data, such as out-of-range values and data (e.g., inverted values in accounts records). These flaws may occur when the data are not validated when transmitting them, impeding some analyses (Singleton, 2013). In most of the Courts, between transmission (or entry) of the data and its "acceptance" by the DCS, the system carries out validations to avoid receiving inconsistent data according to system rules (also known in the software language as business rules or logic). The DCS runs validations during the process of transmitting (at the auditees' side) and receiving (at the Courts' side) the data. After the validation, the data are stored and made available for the use of auditors from the Court. Integrity also includes checking the balances from different periods to control for unacceptable changes of previously transmitted data. For example, the "taxes" account balance at the end of one specific month should be equal to the opening balance in the following month.

\subsection{Mirroring}

Mirroring means the extent to which the transmitted data fully reflects the data stored in the auditee's IFMIS. Possible inappropriate manipulation of the data before transmission (of tax limits, for example) could be mitigated if the accountant transmits the data logged-in in the DCS, taking the responsibility for the data. The quality of the uploaded data could be improved if the incentives to send partial, provisional, or low-quality data (with flaws) were reduced. As some DCSs enables data to be retransmitted, mirroring is reduced, as the data can be altered after the
Courts' analyses. Some Courts prevent retransmission or adopt controlled retransmission.

\subsection{Granularity}

The greater the level of detail in the data, the greater its volume and complexity (Danziger \& Andersen, 2002) and the greater the need for automation. If the information requested by the Court is restricted to the "summarized account balances" of the balance sheet, such data could be easily filled into the DCS webpage (with the risk of errors and manipulations). In contrast, as the level of detail required goes to the transactional level (analytical level), manual data entry becomes unfeasible. Some Courts ask for budgetary execution at a transactional level or/ and supplementary information of chart of accounts (in Portuguese "registros de débito e crédito" and "contas correntes").

\subsection{Frequency}

"Frequency" is the time interval between two reports transmitted to the DCS, comprising two similar datasets but retrieving transactions from different periods recorded in the IFMIS (e.g., April vs. June; 1st quarter vs. 2nd quarter; 2020 vs. 2021). Reporting monthly data (or even daily, as some Courts require for certain information) limits the auditee from making possible accounting adjustments in that month, as the data from previous months have already been reported, which would improve management (Power, 1997). Some collection systems capture data with more frequency or even continuously, enabling simultaneous auditing (Byrnes et al., 2015) and obliging the municipalities to keep their records up-todate. Alternatively, if the data are only collected annually, the accountants are free to adjust the city halls' records for the whole year up to the reporting deadline.

\subsection{Warnings and Analysis}

The DCS uses automatic routines to issue noncompliance warnings and preliminary reports on such occurrences to the auditors and audited public sector organizations. It is a type of simultaneous audit (Huang \& Vasarhelyi, 2019). Among the various uses of the data collected are the provision of: (i) warnings to the auditees, when non-compliance to legal rule is identified, as exceeding fiscal ceilings imposed by FRL; (ii) brief reports for the auditees, presenting warnings on the budgetary, fiscal, or accounting performance; (iii) warnings and situational reports for auditors; and (iv) information for social control on the Court's website. 


\section{THE AUTOMATION TRAJECTORIES OF THE AUDIT OF GOVERNMENTS ANNUAL ACCOUNTS}

Since the launch of the first DCS in 1994, automation in the Brazilian oversight field has four distinct stages that accompanied technological and regulatory waives in the financial management cycle (Figure 1). The main characteristics of the pre-FRL phase (1994-1999) are the search to control spending on personnel (Camata Law I and II - Complementary Law n. 82, of March 27 1995 and Complementary Law n. 96, of May $31^{\text {st, }}$ 1999) and low use of automation and digital tools. At the post-FRL phase (2000-2005) automated fiscal control increased, but ICT remained undervalued to receive financial and human dedicated resources. Next, the Promoex phase (2006-2012) was marked by technological breakthroughs, internet access cost reduction and new technologies, and collaboration between Courts (Silva \& Mário, 2018). Finally, in the postPcasp phase (from 2013 onwards), the Courts adhered to the new unified national chart of accounts and to the new automation features for issue digital financial statements directly from accounting records. The transformation is still underway, currently characterized by an expansion in the scope of the data collected by the Courts, covering issues such as public tenders, procurement or payroll, which go beyond the fiscal-budgetary data already broadly collected.

\subsection{Initial Contexts}

Despite the regulations for the public financial management cycle being the same for the various Courts of Accounts, some contexts may be more favorable for the adoption of DCSs. Some favorable contexts include resources available for investment, skillful teams, technological capabilities in the Courts (Fernandes et al., 2018; Lino \& Aquino, 2018) or in the audited organizations, and the geographic dispersion of municipalities where the Court operates.

At the time of initial adoption, a favorable context for automation would enhance the benefits of the Court being an early adopter (Janowski, 2015) and would encourage a search for productivity gains or legitimacy (Tolbert \& Zucker, 1983). In favorable conditions, the early adopter would assume the cost of developing their own DCS solution or adopt solutions offered by other Courts, even if the solution's effectiveness were uncertain. In contrast, in unfavorable contexts, the Court would wait for already tested solutions, delaying the automation process. We considered Courts as early adopters when they launched their DCS first version before Promoex in 2005 and late adopters from 2006.

Most of the analyzed Courts launched their DCS (at least the first version) by 2005, being considered early adopters (Figure 1). Some started automation before or in the year the
FRL came into effect (eight cases), given that Camata Laws I and II had already established the monitoring of personnel spending. In this first phase, the early adopters launched their self-developed solutions. Only the state of Roraima chose to adopt a pre-existing solution (that of the state of Santa Catarina). Immediately after that, in the second phase (post-FRL - 2000-2005), the FRL led to a rapid expansion of fiscal monitoring; five Courts developed their solutions, and four adopted the state of Santa Catarina's system.

In general, the early adopters had a favorable context for adoption. Several factors explain this initial move: lower auditors/total auditees ratio, geographic dispersion of the public sector organizations audited, and difficult access. In the cases of the states of Espírito Santo and Rio de Janeiro, the lower number of auditees and high geographic concentration would mitigate the benefit of the innovation. Faced with less motivation at that time, Espírito Santo, Acre, Amazonas, and Rondônia invested just timidly on their early DCSs.

\subsection{Path Contingencies}

After the initial adoption, the Courts updated their DCSs' versions, whether to add new technologies or adapt to the regulations. In general, versions were switched through incremental investments to the existing DCS or by substituting it for another new DCS developed by the Court or a version of a DCS granted for use in cooperation with another Court.

Even with constant updates and changes, the evidence indicates that the trajectory of the DCSs was defined mainly by path-dependent mechanisms, such as sunk costs and switching costs, the search for legitimacy, and embeddedness (resistance among technical teams and audited public organizations) (Furneaux \& Wade, 2011; Vergne \& Duran, 2010).

The investments applied to switch versions included creating modules, expanding storage and data processing capacity, tools for auditors to use, auditor training, and the production of handbooks. Two important path-dependent mechanisms are present in the decision to switch versions: auditors and auditees spent resources and time migrating between versions (switching costs), and resources employed in previous versions were lost (sunk costs). Among the early adopters that persisted in their solution, some continuously improved the versions with new features (pattern 1, Table 1), constantly employing resources in ICT teams. Those early adopters managed to overcome the barrier of transition to the web environment. They increased the granularity of the data, automated audit warnings and the issuance of analyses, and improved the integrity of the data. 


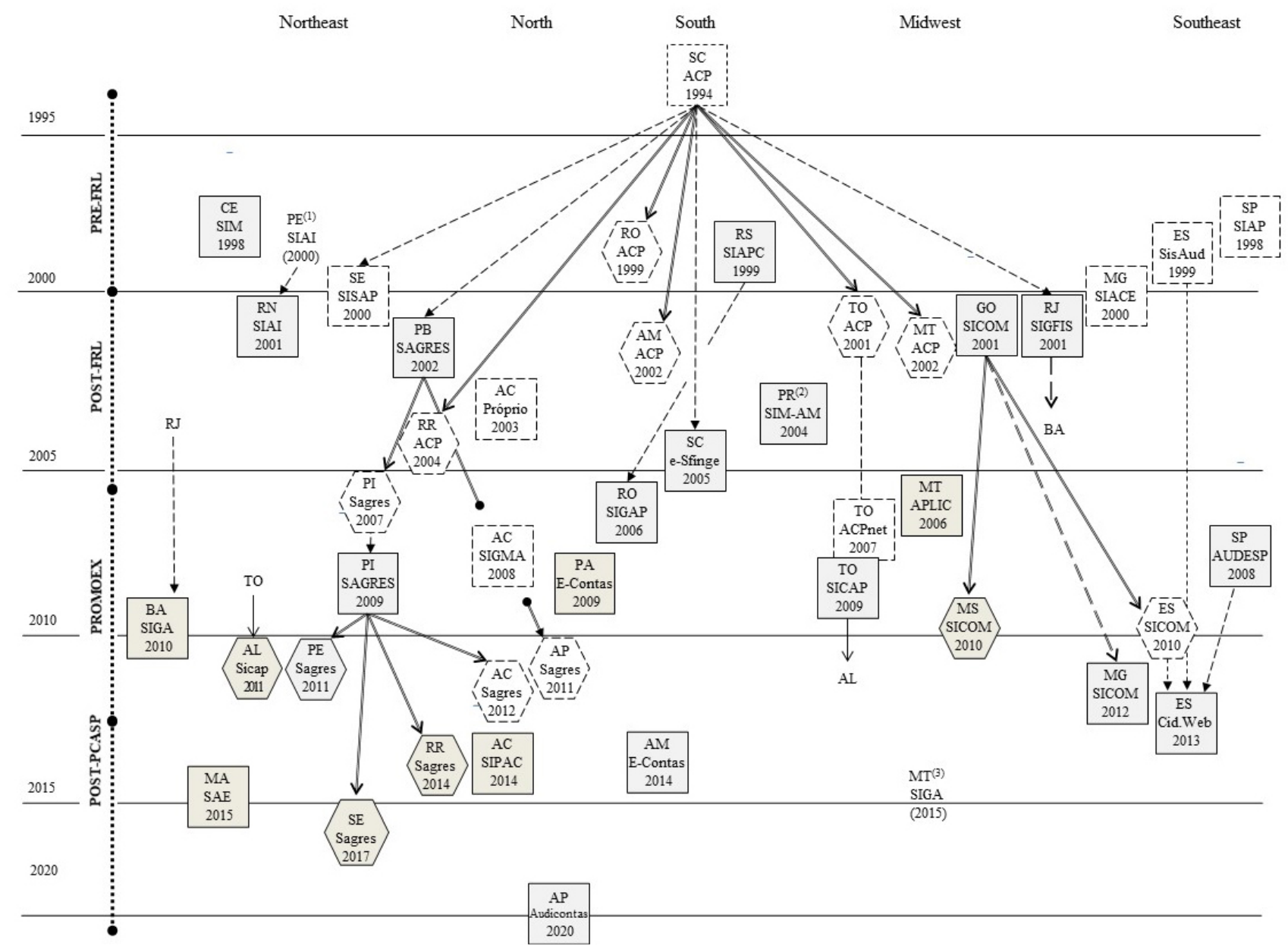

Figure 1 Proliferation of financial data collection systems (DCSs) by the Courts of Accounts (1994-2020)

Notes: The figure presents when each DCS was adopted and its persistence, discontinuation, or change of versions for 26 Courts. There are 26 Courts represented; for those, there are collected evidence allowed to outline the emergence and substitution of versions of DCS.

The following Portuguese-based acronyms for the several DCS mean: ACP = Public Accounts Auditing; ACPnet = Public Accounts Auditing System; APLIC = Computerized Public Accounts Audit; Audesp = Electronic Audit of Public Sector Organizations of the state of São Paulo; Audicontas = Accounts Auditing System; Cid.Web = Computerized system for data receipt of the Espírito Santo Court of Accounts; E-Contas = Information analysis system of the Pará Court of Accounts; E-Sfinge = Integrated Management Auditing System; Promoex = Program for Modernizing the External Control System of the States, Federal District, and Brazilian Municipalities; SAE = Electronic Auditing System; Sagres = System for Monitoring the Management of Society's Resources; SIACE = Computerized System for supporting External Control; SIAI = Integrated Computerized Auditing System; SIAP = Public Administration Information System; SIAPC = Information System for Auditing and Accountability; SICAP = Integrated Public Sector Auditing System; Sicom = Computerized Municipal Accounts System; SIGA = Integrated Management and Auditing System; SIGAP = Integrated Management and Public Sector Auditing Systems; SIGFS = Integrated Tax Management System; SIGMA = Digital Computerized Analysis and Accountability System; SIM = Municipal Information System; SIM-AM = Municipal Information System - Monthly Monitoring; SISAP = Public Sector Auditing System; SisAud = Auditing System.

Brazilian states: $A C=$ Acre; $A L=$ Alagoas; $A M=$ Amazonas; $A P=$ Amapá; $B A=$ Bahia; $C E=C e a r a ́ ; E S=E s p i ́ r i t o ~ S a n t o ; G O=$ Goiás; $M A=$ Maranhão; $M G=$ Minas Gerais; $M S=$ Mato Grosso do Sul; $M T=$ Mato Grosso; $P A=P a r a ́ ; P B=P a r a i ́ b a ; P E=$ Pernambuco; $P I=$ Piauí; $P R=$ Paraná; $R J=$ Rio de Janeiro; $R N=$ Rio Grande do Norte; $R O=$ Rondônia $; R=R o r a i m a ; R S=R i o$ Grande do Sul; $S C=$ Santa Catarina; $S E=$ Sergipe; $S P=$ São Paulo; $T O=$ Tocantins.

Hexagons = the Court adopts a DCS through a cooperation agreement, versions in operation (solid line), or discontinued versions (dashed line). The lines that join the Courts represent a cooperation agreement (solid line) or an influence of the previous system on the current DCS (dashed line); squares = the Court develops a DCS (internally or contracting-it-out), versions in operation (solid line), or discontinued versions (dashed line) - the " $T$ " lines above the squares and the hexagons indicate the DCS development period. $1=$ An auditor developed the SIAI system at the Pernambuco Court of Accounts, created the SIAI, but this system was never used by the Court. 2 = The Paraná Court of Accounts combined the use of two computerized systems from 2001: SIM-PCA and SIMLRF. 3 = Adoption of the SIGA-MT was optional for the municipalities at the time.

Source: Elaborated by the authors. 
Other Courts (pattern 2) only carried out updates and small parametrizations to address changes in the fiscal regulation or make improvements without altering the structure or layout. From 2012 to 2014, they made new investments to update the version of their DCSs to a new national chart of accounts (Pcasp), increasing the path dependence. Thus, the path dependence of pattern 1 is significantly greater than that of pattern 2 due to the sunk costs and the embeddedness with other systems, which are even more bound to their own technological solution trajectory. The use of versions conceded by another Court at some point in the trajectory characterizes other automation patterns (patterns 3, 4, 5, 7, and 8). Two groups of Courts converge around the models raised by systems "Sagres" and "Sicom" (from 2001/2002), which totally or partially influenced eight Courts between 2007 and 2014 (Figure 1). Especially in pattern 1, there was much experimentation in the more peripheral components of the DCS, with the adoption of collection on new issues, discontinuation of others, and constant changes in the data validation rules.

After launching their own DCS, some early adopter
Courts migrated to solutions granted in a cooperation agreement when it was clearer what would be ideal for a typical DCS for Courts of Accounts in Brazil (pattern 3, Table 1).

Other Courts did the inverse, starting with conceded codes [from the Public Accounts Auditing (ACP) of the state of Santa Catarina] they migrated straight away to their self-developed solution (pattern 4, Table 1). These Courts had an unfavorable context for early adoption and chose to start the process with less investment (without development costs).

The states of Acre and Espírito Santo (pattern 5, Table 1) started with their self-developed systems in the first years. They were under comparatively less pressure to adopt and underwent various changes until achieving greater automation.

The state of Piauí, in turn, adopted and improved the system Sagres from Paraíba (pattern 7, Table 1), internalizing greater automation in the short term, but anchored in the previous solution; initially, it did not implement solutions to guarantee data mirroring, such as using XML, which was only adopted in 2014.

Table 1

Trajectory patterns of data collection system (DCS) automation and scope of accounting/fiscal data collected in 2016

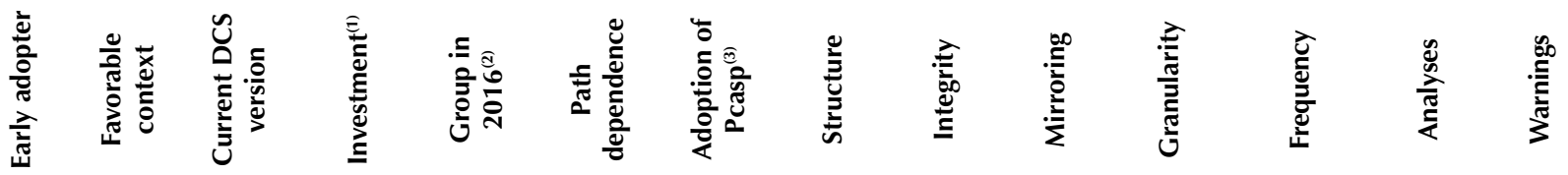

\begin{tabular}{|c|c|c|c|c|c|c|c|c|c|c|c|c|c|c|}
\hline \multicolumn{15}{|c|}{ 1. Constant innovations in their self-developed system } \\
\hline SC & Yes & Yes & 2005 & \multirow{4}{*}{$\begin{array}{l}\text { D, I, } \\
\text { Up, } \\
\text { Imp }\end{array}$} & - & \multirow{4}{*}{$\begin{array}{l}\text { High } \\
\text { and } \\
\text { rising }\end{array}$} & 0 & Yes & Yes & Yes & Yes/dc & Bimonthly & Yes & Yes \\
\hline GO & Yes & Yes & 2001 & & - & & -2 & Yes & Yes & Yes & Yes/si & Monthly & Yes & No \\
\hline SP & Yes & Yes & 2008 & & - & & -2 & Yes & Yes & Yes & Yes/si & Monthly & Yes & Yes \\
\hline PR & Yes & Yes & 2004 & & - & & -2 & Yes & Yes & Yes & Yes/dc & Monthly & Yes & Yes \\
\hline \multicolumn{15}{|c|}{ 2. Self-developed systems with little innovation } \\
\hline $\mathrm{RN}$ & Yes & Yes & 2001 & \multirow{4}{*}{$\begin{array}{c}\text { D, I, } \\
\text { Up }\end{array}$} & - & \multirow{4}{*}{$\begin{array}{l}\text { Low } \\
\text { and } \\
\text { Stable }\end{array}$} & 0 & Yes & Yes & No & Yes/si & Bimonthly & Yes & Yes \\
\hline CE & Yes & Yes & 1998 & & - & & -1 & Yes & Yes & No & Yes/si & Monthly & Yes & No \\
\hline RS & Yes & Yes & 1999 & & - & & -1 & Yes & Yes & No & No & Bimonthly & Yes & Yes \\
\hline $\mathrm{RJ}$ & Yes & No & 2001 & & - & & 0 & Yes & No & No & No & Monthly & Yes & No \\
\hline \multicolumn{15}{|c|}{ 3. Self-developed solution to later granted code } \\
\hline $\mathrm{PE}$ & Yes & Yes & 2011 & \multirow{2}{*}{$\begin{array}{c}\text { D, I, } \\
\text { Up }\end{array}$} & Sagres & \multirow{2}{*}{$\begin{array}{l}\text { Low } \\
\text { after } \\
\text { sunk } \\
\text { cost }\end{array}$} & -2 & Yes & Yes & Yes & Yes/si & Monthly & Yes & No \\
\hline MG & Yes & Yes & 2012 & & Sicom & & 0 & Yes & No & Yes & Yes/si & Monthly & Yes & Yes \\
\hline \multicolumn{15}{|c|}{ 4. Granted code to later self-developed system } \\
\hline $\mathrm{RO}$ & Yes & No & 2006 & \multirow{3}{*}{$\begin{array}{c}\text { D, I, } \\
\text { Up }\end{array}$} & - & \multirow{3}{*}{ Rising } & -2 & Yes & Yes & Yes & No & Monthly & Yes & Yes \\
\hline AM & Yes & No & 2014 & & - & & -2 & Yes & Yes & Yes & Yes/si & Monthly & No & No \\
\hline MT & Yes & Yes & 2006 & & - & & 0 & Yes & Yes & Yes & Yes/si & Monthly & Yes & Yes \\
\hline
\end{tabular}


Table 1

Cont.

\begin{tabular}{|c|c|c|c|c|c|c|c|c|c|c|c|}
\hline 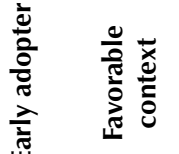 & 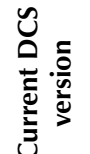 & 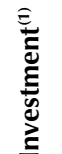 & 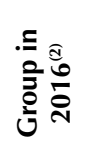 & 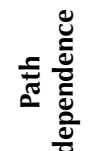 & 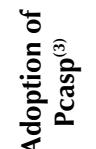 & 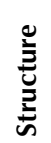 & 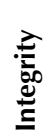 & 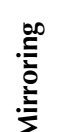 & 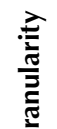 & 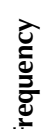 & $\frac{\mathscr{d}}{\frac{\mathscr{n}}{\hat{\sigma}}}$ \\
\hline
\end{tabular}

5. Multiple changes

\begin{tabular}{|c|c|c|c|c|c|c|c|c|c|c|c|c|c|c|}
\hline$A C$ & Yes & No & 2014 & & Sagres & Low & -1 & Yes & Yes & Yes & Yes/si & Monthly & Yes & No \\
\hline ES & Yes & No & 2013 & $\begin{array}{l}\text { Up, } \\
\text { Imp }\end{array}$ & Sicom & $\begin{array}{c}\text { sunk } \\
\text { cost }\end{array}$ & -2 & Yes & Yes & Yes & Yes/dc & Bimonthly & Yes & Yes \\
\hline
\end{tabular}

6. Later self-developed system

\begin{tabular}{|c|c|c|c|c|c|c|c|c|c|c|c|c|c|c|}
\hline BA & No & Yes & 2010 & $\begin{array}{l}\text { D, I, } \\
\text { Up, } \\
\text { Imp }\end{array}$ & - & Rising & -2 & Yes & No & Yes & No & Monthly & Yes & No \\
\hline \multicolumn{15}{|c|}{ 7. Improves granted code } \\
\hline PI & No & Yes & 2009 & $\begin{array}{l}\text { I, Up, } \\
\text { Imp }\end{array}$ & Sagres & Rising & -1 & Yes & Yes & Yes & Yes/si & Monthly & No & No \\
\hline \multicolumn{15}{|c|}{ 8. Later granted code } \\
\hline MS & No & No & 2010 & I, Up & Sicom & Low & -2 & Yes & Yes & Yes & Yes/si & Monthly & Yes & No \\
\hline
\end{tabular}

Notes: The Table covers 18 Courts that answered the questionnaire and were interviewed regarding their choices related to investing in their own DCS, adopting one from another Court through a cooperation agreement, incrementally adapting their current one, or switching DCS and discontinuing the previous one. In the case of the state of Ceará, the description of the DCS was obtained in the Court of Accounts of the Municipalities of Ceará, incorporated by the State Court of Accounts in 2017.

(1) Investments in information technology made by the Court (Imp = improvement of the DCS, with costly adoption of new features; $U p=$ updating of the DCS and small parametrizations to address changes in the rules or make improvements, without altering the structure or layout of the DCS; I = implementation of the DCS; D = design, and development of the DCS); (2) Group with greater homogeneity in the DCS in operation in 2016; (3) Early adoption (in years) of the standardized national chart of accounts [Chart of Accounts Applied to the Public Sector (Pcasp)] in relation to the last adoption deadline set by the National Treasury Secretariat in 2015.

si = supplementary information of chart of accounts is requested; $d c=$ debit and credit records are requested; Sagres = System for Monitoring the Management of Society's Resources; Sicom = Computerized Municipal Accounts System.

Brazilian states: $A C=$ Acre; $A L=$ Alagoas; $A M=$ Amazonas; $A P=$ Amapá; $B A=$ Bahia; $C E=C e a r a ́ ; E S=E s p i ́ r i t o ~ S a n t o ; G O=$ Goiás; $M A=$ Maranhão; $M G=$ Minas Gerais; $M S=$ Mato Grosso do Sul; $M T=$ Mato Grosso; $P A=P a r a ́ ; P B=P a r a i ́ b a ; P E=$ Pernambuco; $P I=$ Piauí; $P R=$ Paraná; $R J=$ Rio de Janeiro; $R N=$ Rio Grande do Norte; $R O=$ Rondônia; $R R=R o r a i m a ; R S=R i o$ Grande do Sul; $S C=$ Santa Catarina; $S E=$ Sergipe; $S P=$ São Paulo; $T O=$ Tocantins.

Source: Elaborated by the authors.

Other Courts that were not in such as hurry to adopt early adopted the Sicom or Sagres system (pattern 8, Table 1) and advanced in automation with the same initial limitation of the state of Piauí, in terms of a low mirroring level. Finally, some Courts had difficulties launching their self-developed systems. The states of Bahia, Maranhão, and Pará (pattern 6, Table 1) developed their systems but with a low level of effective automation. These would, a priori, have a favorable context for innovation, but besides entering late, they faced difficulties in the fourth phase. Compared to the DCSs developed internally, those adopted through cooperation agreements had lower sunk costs and therefore faced less resistance from the teams of the Court. In any case, changing versions (own or granted) brings switching costs to the whole chain, affecting IFMIS providers and client municipalities (see below).

\subsection{Exogenous Shocks}

Disruptive technological or regulatory changes reduce the lock-in of a solution (Furneaux \& Wade, 2011; Schneiberg, 2007; Vergne \& Duran, 2010). Two shocks could be considered as exogenous and prompting or driving the practices of government reporting in Brazil, including the emergence and change of DCSs. First, the establishment of the FRL led to a transition from the analogical mode to the digital one for data collection, given the increased requirement for the Courts to monitor government fiscal performance. However, the sunk costs of development and training would continuously decrease as the updated versions of DCSs solve the gaps of the early versions. 
The second shock was the compulsory adoption of a new national chart of accounts (Pcasp) in 2013, which was not enough to reduce the lock-in of the older trajectories. The adoption of a nationally standardized chart of accounts is iconic for the oversight field. Depending on how the DCS's proprietary source code was programmed, for instance, including the chart of accounts embedded in the code, it can be unfeasible to search for modifications among thousands or millions of lines of code. Suppose the electronic protocol to receive data (which reflects and is organized around a "chart of accounts") is defined by the source code; any changes on the chart will reach the deepest layers of the system, with a greater chance of abandoning the previous solution.

Most of the Courts anticipated the adoption of the standardized chart of accounts (Pcasp), launching the use of the new chart one or two years before the deadline set by the National Treasury (Table 1). For example, the Courts of the states of Goiás, São Paulo, and Paraná adopted the new chart two years in advance. These Courts (pattern 1) had already incurred higher sunk costs and again incurred the costs of adapting their DCSs to the new chart. On the other hand, the Courts with shared solutions with other
Courts, which had already incurred sunk costs from their previous versions, migrated with few losses to solutions adapted to the new chart. This was the case of the state of Espírito Santo, which discontinued its version of Sicom in 2010 (at the time not adapted to the new chart of accounts, as this DCS was only adapted to the new chart in 2014 by the state of Goiás) to adopt CidadesWeb (a version inspired by São Paulo system Audesp). Currently, the DCSs already foresee periodic adaptations of the chart of accounts with low-cost operational updates.

Despite the technological and regulatory shocks reducing lock-in in the DCSs, the changes resulting from these shocks cause instability in the financial management infrastructure of governments and reduce the willingness of these governments to make new investments. As the dominant IFMIS model in the country is an outsourced one (Azevedo, Lino, Martins \& Aquino, 2020), governments transfer the risk of obsolescence to private sector IFMIS providers and outsource their ICT and accounting teams. We also identified less frequent IFMIS arrangements in place, as the use of free software or modular systems developed by one Court itself and granted to the auditees to use for free.

\section{THE EMBEDMENT OF DIGITAL INFRASTRUCTURES}

Path dependence is one of the probable reasons for the embeddedness of digital infrastructures (Fürstenau et al., 2019), establishing the main characteristics at the center of the infrastructure. Such characteristics, when changed, would cause high switching or sunk costs. As already presented, the trajectories of the DCSs are the center of the digital infrastructure for collecting fiscal data in Brazil.

In the period analyzed, various interviews indicate that the DCS became a fundamental means through which data circulate for the oversight of public sector organizations, connecting the Courts' auditors with the municipalities audited. As mentioned, the trajectories of the various DCSs in operation avoided switching or sunk costs, but they contain a degree of latent path dependence. In the absence of other external shocks (rather than the Pcasp compulsory adoption), the Courts avoided switching and sunk costs; they accepted a suboptimal level of functionality and condensed their innovations into incremental features over the current trajectory. Thus, over the long run, the transformation of the oversight and government auditing field as a whole ceased to be radical. This transformation in the oversight field derives from the DCS itself as the center of a digital infrastructure.

The path-dependent mechanisms that influenced the DCS innovations decisions also involve switching costs and risks of sunk costs at both sides of the digital infrastructure. At one end, accountants operate the IFMISs of the municipalities reporting data, revising accounting and budgetary records policies to the changes in regulation and DCS, and at the other end, the computer-assisted audit tools, when used by auditors to run the collected data, shape routines, scope, and auditing plans. The influence of the DCS's electronic protocols also affects the processes and modules of the other satellite systems of the IFMIS (called structuring systems by Decree n. 10,540 [2020, November $\left.5^{\text {th }}\right]$ ), but in a non-uniform way, which can make the ongoing module integration a real challenge.

The influence of the DCS's electronic protocols also reaches handbooks and training on reporting tasks and, primarily, the routines of the civil servants and consultants carrying out this task in municipalities, as seen in the study 
by Tilson et al. (2010). It implies that switching versions of the DCS affects the whole government auditing value chain because it affects the entire digital infrastructure. By changing a version of the DCS, the Court of Accounts imposes costs on the whole chain of stakeholders, audited organizations, and local government accounting and budgeting service providers. Depending on the changes imposed, the cost of implementation and disruptions in the process can lead to a systemic compliance loss to the oversight process by the auditees of that Court.

This transformation has occurred silently and incrementally due to the system embeddedness (Furneaux \& Wade, 2011; Fürstenau et al., 2019). Evidence of path dependence in this interconnection of systems in the infrastructure is how the Courts consider the risk of switching DCS versions and the impact on auditees. For example, Courts postponed adopting a new version of DCS when they detected that most municipalities would be late in reporting data, or there would be a reduction in the quality of reported data due to a lack of resources or limitations in the auditee's IFMIS. The development of a DCS is intimately related to how the stakeholders connected to the digital infrastructure will respond to changes. The Court aims not to exceed the capacity of its auditees to adapt to the proposed changes, as reported in interviews: "we did not implement it before because the municipalities were unable to, and they would not have sent the data." One solution frequently adopted by Courts that innovate in their DCSs is incremental change, in which new versions are launched recurrently. However, for the audited organizations, this model implies constant adaptations and an increase in adaptation costs along with accountability overload. An additional challenge for the Courts with multiple auditees is to deal with possible heterogeneity of the administrative and financial infrastructure of the public organizations it audits, which would enable the convergence of its digital infrastructure. A similar effect was identified by Bjorn et al. (2010).

The expansion of digital infrastructures is a living phenomenon, and it is still underway. It started with DCSs entering the oversight field and is now moving to increased use of computer-assisted audit tools. In this period, the continuous use of a digital infrastructure reinforced organizational processes and routines (system embeddedness), as discussed by Furneaux and Wade (2011). The development of various digital infrastructures also embeds concepts and definitions (e.g., "data transmission," "non-compliance warnings"), expectations (e.g., the value chain adapts to its systems), and a logic of action (e.g., data are reported remotely, the auditor's time is freed up for other tasks, and the audited organization incurs the reporting cost) (Aquino, Lino, Azevedo \& Silva, 2021).

In the field of public sector auditing in Brazil, the presence of more than 30 digital infrastructures maintained by the Courts, connecting more than five thousand municipalities, creates a market for experts, the development of systems providers, and knowledge sharing. As they stabilize and converge in some aspects, the trajectories analyzed ultimately shape the general trajectory of transformation of the oversight field until external shocks alter the trajectory. This effect is reinforced by other initiatives, such as those of the Health Ministry, Education Ministry, and the National Treasury, which add additional complexity, meaning that the same municipality must comply with an agenda for reporting data to various DCSs.

\section{IMPLICATIONS FOR OVERSIGHT FIELD}

The Courts of Accounts' capacity to point out irregularities depends on their teams, resources, and political pressures and motivations (Lino \& Aquino, 2018, 2020). The results indicate that the data collection process can also positively affect the quality of the activities of the audit organizations. For example, interviewees raise productivity gains, such as a cost reduction in storing paper documents. The interviews also indicate that, along with the benefits of innovation in auditing processes, the proliferation of DCSs in the local government's oversight develops a digital infrastructure that affects the entire chain of government auditing and financial management, implying some threats (Ghoneim et al., 2011).

First, the constant switching of versions of DCSs can weaken the financial management (software, processes, and staff training) of audited governments. As local government's IFMISs are integrated into the Courts DCS, switching DCS causes sunk costs, both from the DCS and from the IFMIS, for the whole chain. Moreover, it adds switching costs, as it requires adaptations of the IFMIS versions and processes or turns such systems obsolete. 
The abrupt and constant switching of versions of DCSs brings uncertainty about how feasible it is to follow a brand-new launched version promptly or if it is better to wait for another one. It discourages auditees' investments in system parametrization and integration and staff training. As the integration between the DCS and IFMIS is essential for the frequent exchange of granular data, the data collection process itself is negatively affected. Moreover, as IFMIS providers experience difficulties in passing on these costs within the client portfolio, they prioritize the parametrizations that the Courts of Accounts value the most, and with these providers define the operationalization of the reform agenda in the public sector, with little influence from the accounting standardsetter (Azevedo, Aquino, Neves, \& Silva, 2020).

The continuous changes can also cause small commercial IFMIS providers to leave this market segment as they are unable to keep their solutions up to date in a competitive environment of widespread legal changes and innovations imposed by the DCSs. Moreover, some Courts of Accounts classify IFMIS packages as a commodity, do not allow governments to contract based on technical features, imposing low-cost bidding and enforcing price competition, which reduces investments in software development (Azevedo, Lino, Martins, \& Aquino, 2020). Financial management and accounting practices development for the entire federation may ultimately be made more complex and less homogenous than previously considered.

Second, the differences in attributes of the various DCSs in use can lead to greater diversity in those Courts' activities. Compared with the analogical and physical reporting rituals previously in place, data collection automation opens up new possibilities regarding the granularity, frequency, and use of the collected data. However, potential differences in attributes of the DCS that have not converged yet tend to widen pre-existing differences (i) between the financial management processes and systems in Brazilian municipalities, (ii) in the activities of the Courts depending on the volume of data collected, and (iii) in the interpretations regarding the FRL carried by DCS's logic and protocols. These differences are not always observed by auditors (Aquino, Lino, Azevedo \& Silva, 2021).

Third, automation contributes to defining the audit and accounting processes in Courts and the audited public organizations. In the Courts, the DCS mirrors the Court's decisions regarding prioritized content, defining the data stored and, therefore, the future consequences of remote auditing, as well as potential applications of artificial intelligence in those databases. Also, in the Courts, investment in DCSs focused just on financial-accounting issues can reduce operational or performance auditing efforts. In turn, in the public sector organizations audited, the DCS outlines the internal control accounting processes (e.g., recognition, measurement, and recording) as well as the adoption of IFMIS modules (Aquino, Azevedo, Lino, \& Cardoso, 2021).

The definition of the set of data to be collected also directly influences the "real" management in the audited organizations. These public sector organizations tend to prioritize maintaining and improving processes associated with the data collected by the Court of Auditor's DCS, unlike the processes not yet covered by the DCS, which lose priority even if there is a legal requirement. One example of this is the prioritizing of fixed asset management, which produces data collected by the DCS, while tax subsidies are not monitored, not collected, and the organizations are not improving their management. Within a context such as this, processes are improved by the audited government looking just for compliance.

Fourth, the context of accountability overload due to the increase in multiple data collections imposed on municipalities consumes growing resources to maintain a dedicated reporting team (Halachmi, 2014). The negative effect is intensified when multiple DSCs collect data of the same nature but with different accounting recommendations, conflicting standards, and encouraging different practices. One example is the alteration in budgetary classifiers of revenue, which, despite being requested by the National Treasury (Joint Ordinance $n$. 1,2017 , September $15^{\text {th }}$ ), was not timely adapted by the Health Ministry's DCS. Hence, auditees faced two different and conflicting requests that year.

Other effects that appear to be present in the field are the false expectations of the reach of remote auditing (Azevedo \& Lino, 2018) and biases in remote auditing. Using automatic verification of non-compliance of data focused on budgetary, fiscal, and accounting aspects can create a false expectation of information quality and compliance (Azevedo \& Lino, 2018). For example, not all aspects of the tax and other regulations are monitored by the Court. Particularly in a national analysis, the perception can be even more different from the reality, as each DCS has a different scope and uses different granularity in its collection. The auditing bias originating from the use of computer-assisted tools was recently discussed in more detail by Aquino, Lino, Azevedo, and Silva (2021). Briefly, the automation of auditing with a fiscal-budgetary focus will emphasize remotely verifying observable non-compliance in the data collected rather than non-compliance that is only observable in the physical or electronic processes that occur in the audited organization. 


\section{CONCLUSIONS}

In the last 26 years, the automation of data collection from auditees of the Courts of Accounts has developed with the Courts adopting DCSs. Over time, these DCSs have transformed into digital infrastructures, transporting data originating from the IFMIS of municipalities to the computer-assisted audit tools used by auditors. We observed eight different development trajectories of the DCSs, which in turn had some degree of influence on the digital infrastructures of these Courts, ranging from the collection to the use of the data by the auditors.

The trajectories mostly follow path-dependence mechanisms and the occurrence of lock-in. Despite that, we recognize that the actions of these mechanisms are not fully verifiable and distortable (Vergne \& Duran, 2010). Highlighting these methodological limitations, we suggest viewing the path-dependence here as a possible driving force in the trajectory in the oversight field and not a complete and definitive explanation for the process. There is an observed convergence of attributes around a typical DCS, but the differences between the DCSs in operation can intensify the differences between the Courts that have already been identified (Azevedo \& Lino, 2018; Lino \& Aquino, 2018; Nunes et al., 2019) and cause a heterogeneous inducement of reforms in the financial management cycle of governments (Bjorn et al., 2010).

The phenomenon analyzed is a living and dynamic process. The period from 1994 to 2020 shows only the start of the emergence of the digital infrastructures of the Courts and the convergence of the fiscal data collection tools and the remote auditing logic (Aquino, Lino, Azevedo, \& Silva, 2021). The Courts continue to review their solutions under external pressures, such as the convergence to the National Treasury's framework to report financial data (in Portuguese: 'Matriz de Saldos Contábeis') and frequent changes in the regulations.

Some solutions could be adopted to address the possible adverse effects foreseen in the previous section. Through a National Council of Courts of Accounts (similar to what already occurs in the Brazilian judiciary branch), an association (such as the Association of Members of the Courts of Accounts of Brazil [Atricon], or the Rui Barbosa Institute), the Courts could actively develop and coordinate an automation logic instead of merely reacting to technological and regulatory changes. Such active coordination would engage municipalities and providers to discuss a maturity framework for the fiscal data collection process and, therefore, to better support projects for integrating IFMISs, whether through free software or certification of commercial solutions.

Some reflections for future research can be listed. First, digital infrastructures, like any digital artifact in organizations, are not only technological material but also coordination tools. Despite the technological modernization underway, the Courts have not yet started to improve their governance and have drawn serious criticisms in this regard (Lino \& Aquino, 2020). Some of the protocols embedded in DCSs may carry influences from the current politicization in the Courts and act as a source of systemic power. Second, despite the nationally standardized legislation, there is a lack of symmetry between the many Courts of Accounts in practice. Different prioritizations are observed in the set of data to be collected by municipalities and in their level of detail, which may also be more representative of political than merely technological effects. Third, these infrastructures contain a normative burden, and they shape what has the greatest and least value and how things should be done, continuously being crystallized by the digital infrastructure. From an institutional perspective, the introduction and proliferation of these infrastructures may reinforce the logic of remote auditing and can promote (without any awareness) the interests of powerful and influential players in the oversight field. These powerful players have access to resources to design the digital infrastructure according to specificities to fit their interests, shaping the behavior of auditors and accountants as other less powerful job positions, whether in the Courts or the audited organizations.

As highlighted, the automation trajectories of data collection by Courts of Accounts are a live phenomenon but consolidated. The features and attributes associated with the DCSs compose digital infrastructures and embed both auditor and accountant behaviors. Despite the benefits associated with automation, various unexpected effects of the proliferation of digital infrastructures have been pointed out. There is a need for greater reflection regarding the technology applied, both in terms of its antecedents (motivations) and its effects on financial and accounting management. 


\section{REFERENCES}

Alles, M. G., \& Vasarhelyi, M. A. (2007). The need to reengineer the business reporting process. International Journal of Disclosure and Governance, 4(3), 204-216.

Aquino, A. C. B. de, Lino, A. F., Azevedo, R. R. de, \& Silva, P. B. da. (2021). Digital infrastructure embeddedness and public audit side-effects. Financial Accountability \& Management. Manuscript submitted for publication.

Aquino, A. C. B de, Azevedo, R. R. de, Lino, A. F., \& Cardoso, R. L. (2021). Financial management information systems. Manuscript in preparation.

Azevedo, R. R. de, \& Lino, A. F. (2018). O distanciamento entre as normas de auditoria e as práticas nos Tribunais de Contas. Sociedade, Contabilidade e Gestão, 13(2), 9-27.

Azevedo, R. R. de, Lino, A. F., Martins, T., \& Aquino, A. C. B. de (2020). Financial management information systems and accounting policies retention in Brazil. International Journal of Public Sector Management, 33(2/3), 207-227.

Azevedo, R. R. de, Aquino, A. C. B. de, Neves, F. R., \& Silva, C. M. da. (2020). Deadlines and software: Disentangling local government accounting gradual reforms in Brazil. Public Money \& Management, 40(7), 509-518.

Arnold, V. (2018). The changing technological environment and the future of behavioural research in accounting. Accounting and Finance, 58(2), 315-339.

Bradford, M., Henderson, D., Baxter, R. J., \& Navarro, P. (2020). Using generalized audit software to detect material misstatements, control deficiencies and fraud: How financial and its auditors perceive net audit benefits. Managerial Auditing Journal, 35(4), 521-547.

Byrnes, P. E., Al-Awadhi, A., Gullvist, B., Brown-Liburd, H., Teeter, R., Warren, J. D., Jr., \& Vasarhelyi, M. (2015). Evolution of auditing: From the traditional approach to the future audit. In Audit analytics and continuous audit (pp. 7185). American Institute of Certified Public Accountants.

Complementary Law n. 82, of March $27^{\text {th }} 1995$ (1995, March $\left.28^{\text {th }}\right)$. Defines civil service spending limits, in the form of art. 169 of the Federal Constitution. (Camata Law) http://www.planalto. gov.br/ccivil_03/leis/lcp/lcp82.htm

Complementary Law n. 96, of May $31^{\text {st }} 1999$. (1999, June $1^{\text {st }}$ ). Defines personnel spending limits, in the form of art. 169 of the Constitution. http://www.planalto.gov.br/ccivil_03/leis/ lcp/lcp96.htm.

Complementary Law n. 101, May $4^{\text {th }} 2000$. (2000, May $\left.4^{\text {th }}\right)$. Establishes public finance rules focusing on responsible fiscal management and sets out other arrangements. http://www. planalto.gov.br/ccivil_03/leis/lcp/lcp101.htm

Danziger, J. N., \& Andersen, K. V. (2002). The impacts of information technology on public administration: An analysis of empirical research from the "golden age" of transformation. International Journal of Public Administration, 25(5), 591-627.

Decree n. $10,540\left(2020\right.$, November $\left.5^{\text {th }}\right)$. Discusses the minimum quality standard of the Single and Integrated Budgetary Execution, Financial Administration, and Control System. https://www.in.gov.br/en/web/dou/-/decreto-n-10.540-de-5de-novembro-de-2020-286682565

Elliott, J., Holland, J., \& Thomson, R. (2008). Longitudinal and panel studies. In The SAGE handbook of social research methods (pp. 228-248). SAGE Publications.

Fernandes, G. A. A. L., Fernandes, I. F. L. A., \& Teixeira, M. C. (2018). Estrutura de funcionamento e mecanismos de interação social nos Tribunais de Contas estaduais. Revista do Serviço Público, 69(special edition), 123-150.

Flick, U. (1998). An introduction to qualitative research. SAGE Publications.

Fligstein, N. (1985). The spread of the multidivisional form among large firms, 1919-1979. American Sociological Review, 50(3), 377.

Furneaux, B., \& Wade, M. R. (2011). An exploration of organizational level information systems discontinuance intentions. Mis Quarterly, 35(3), 573-598.

Fürstenau, D., Baiyere, A., \& Kliewer, N. (2019). A dynamic model of embeddedness in digital infrastructures. Information Systems Research, 30(4), 1319-1342.

Ghoneim, A., Irani, Z., \& Sahraoui, S. (2011). Guest Editorial. European Journal of Information Systems, 20, 303-307.

Halachmi, A. (2014). Accountability overloads. In The Oxford handbook of public accountability (pp: 560-573). Oxford University.

Hermanns, H. (1995). Narratives Interview. In U. Flick, E. V. Kardorff, H. Keupp, L. V. Rosenstiel, \& S. Wolff (Eds.), Handbuch qualitative sozialforschung (pp. 182-185). Psychologie Verlags Union.

Huang, F., \& Vasarhelyi, M. A. (2019). Applying robotic process automation (RPA) in auditing: A framework. I. Journal of Accounting Information Systems, 35, Article 100433.

Janowski, T. (2015). Digital government evolution: From transformation to contextualization. Government Information Quarterly, 32(3), 221-236.

Kay, A. (2005). A critique of the use of path dependency in policy studies. Public Administration, 83(3), 553-571.

Joint Ordinance n. 1 (2017, September $\left.15^{\text {th }}\right)$. Alters Interministerial Ordinance STN/SOF n. 163, of May $4^{\text {th }}$ 2001. https://www.in.gov.br/materia/-/asset_publisher/ Kujrw0TZC2Mb/content/id/19296327/do1-2017-09-18portaria-conjunta-n-1-de-15-de-setembro-de-2017-19296202

Lino, A. F., \& Aquino, A. C. B. de. (2018). A diversidade dos Tribunais de Contas regionais na auditoria de governos. Revista Contabilidade \& Finanças, 29(76), 26-40.

Lino, A. F., \& Aquino, A. C. B. de. (2020). Práticas não adequadas nos Tribunais de Contas. Revista de Administração Pública, 54(2), 220-242.

Loureiro, M. R., Teixeira, M. A. C., \& Moraes, T. C. (2009). Democratização e reforma do Estado: o desenvolvimento institucional dos Tribunais de Contas no Brasil recente. Revista de Administração Pública, 43(4), 739-772. 
Mergel, I., Edelmann, N., \& Haug, N. (2019). Defining digital transformation: Results from expert interviews. Government Information Quarterly, 36(4), Artigo 101385.

Nunes, S. P. P., Marcelino, G. F., \& Silva, C. A. T. (2019). Os Tribunais de Contas na interpretação da Lei de Responsabilidade Fiscal. Revista de Contabilidade e Organizações, 13(e145151).

Power, M. (1997). The audit society: Rituals of verification. Oxford University.

Reichertz, J. (2013). Induction, deduction. In The Sage handbook of qualitative data analysis (pp: 123-135). Sage Publications.

Reis, A. F., Dacorso, A. L. R., \& Tenório, F. A. G. (2015). Influência do uso de tecnologias de informação e comunicação na prestação de contas públicas municipais um estudo de caso no Tribunal de Contas dos Municípios do Estado da Bahia. Revista de Administração Pública, 49(1), 231-251.

Ruttan, V. W. (2001). Sources of technical change: Induced innovation, evolutionary theory, and path dependence. In R. Garud, \& P. Karnøe (Eds.), Path dependence and creation (pp: 91-123). Lawrence Erlbaum.

Schneiberg, M. (2007). What's on the path? Path dependence, organizational diversity and the problem of institutional change in the US economy, 1900-1950. Socio-Economic Review, 5(1), 47-80.

Scott, R. W. (2014). Institutions and organizations. Ideas, interests, and identities (4a. ed.). SAGE Publications.
Silva, F. de A., \& Mário, P. do C. (2018). Análise do programa de modernização do controle externo brasileiro. Sociedade, Contabilidade e Gestão, 13(2), 79-96.

Singleton, T. W. (2010). Data extraction, a hindrance to using CAATS. ISACA Journal, 6, 7-9.

Singleton, T. W. (2013). What every it auditor should know about transforming data for CAATS. ISACA Journal, 6, 12-15.

State Auditor's Office. (2021, March $\left.9^{\text {th }}\right)$. Office of the Washington State Auditor. https://www.sao.wa.gov

Teeter, R. A., Alles, M. G., \& Vasarhelyi, M. A. (2010). The remote audit. Journal of Emerging Technologies in Accounting, 7(1), 73-88.

Teixeira, M. D. S. (2020). Courts of accounts divergent methodologies and its impacts on personnel expenditure rules. Revista de Administração Pública, 54(6), 1747-1759.

Tilson, D, Lyytinen K, \& Sørensen C. (2010). Digital infrastructures: The missing IS research agenda. Information Systems Research, 21(4), 748-759.

Tolbert, P. S., \& Zucker, L. G. (1983). Institutional sources of in the formal change structure of organizations: The diffusion of civil service reform, 1880-1935. Administrative Science Quarterly, 28(1), 22-39.

Vergne, J. P., \& Durand, R. (2010). The missing link between the theory and empirics of path dependence: Conceptual clarification, testability issue, and methodological implications. Journal of Management Studies, 47(4), 736-759. 